\title{
Evaluating the Radiological Health Compliance of some Beach Environments in Delta State
}

\author{
${ }^{* 1}$ MOKOBIA, CE; ANIKU, T; AVWIRI, G \\ *Department of Physics Delta State University Abraka, Nigeria \\ +Department of Physics University of Port Harcourt, Nigeria \\ Corresponding Author: cmokobia@ymail.com
}

\begin{abstract}
Beaches constitute recreational and resort centres in the environment of which radiation is part. With respect to radiation protection practice, the International Radiation Protection bodies from time to time recommend certain exposure limits for different environments. In this study, a Raderlert 100 radiation meter was used to measure the gamma radiation levels in four beaches in Delta State, Nigeria. The purpose is to ascertain whether or not the radiation levels in these resort centres conform with international stipulations and consequently infer if their respective environments are radio logically health compliant such that personnel as well as specified members of the public (customers) are not at radiological risk. Results indicate a dose rate range of $(0.010-0.015) \mathrm{mRh}^{-1}$. These are generally higher than the $0.013 \mathrm{mRh}^{-1}$ recommendation of ICRP. Results also indicate an Annual Effective Dose Equivalent AEDE range of $(0.19-1.598) \mathrm{mSvy}^{-1}$ which are higher than the recommended 1 $\mathrm{mSvy}^{-1}$. Results further indicate an Excess Life Cancer Risk ECLR range of $(0.64-1.74) \times 10^{-3}$. These are higher than the $0.29 \times 10^{-3}$ world average. Thus it is concluded that the radiation levels in the environments of the studied beaches exceed international radiation regulatory stipulations. Therefore, in this their present states, these environments are radio logically unhealthy for their respective workers and members of the public. @JASEM
\end{abstract}

\section{http://dx.doi.org/10.4314/jasem.v20i3.4}

Key Words: Radiation levels; Beaches; Radiological health compliance

Beaches can be defined as landforms found along the shoreline of water bodies. They are most of the time composed of loose particles. These have been found to be made up of rock, sand, gravel, and pebbles (Blair and Dawn, 2007). Notable among some of the social/ economic values as identified by literature are income and employment generation. They are also acclaimed for the provision of tourism and holiday resort environments throughout the world.

As subsets of the environment, they are indisputably exposed to radiation from different sources some of which are natural while others are anthropogenic. The effects of radiation on humans are well documented in literature (UNSCEAR, 2013). Of particular note is its cancer causation for high exposures and mental retardation in children whose mothers are exposed to radiation during pregnancy (Rafique et al; 2014).

The list of renowned beaches in the world is endless. A few of these and their locations are presented in Table 1. Delta State, Nigeria $\left(5.5000^{\circ} \mathrm{N}, 6.0000^{\circ} \mathrm{E}\right)$ is blessed with a number of rivers, streams and creeks and also favoured with a number of natural beaches a bulk of which are yet to be developed. There have been recent efforts to improve the tourism industry in this State. These efforts portend renewed acknowledgment of the relevance of these land forms. As more of these are developed and put into use, an area that should be of concern to environmental radiation protection agencies, governments as well as the operators of these centres is the radiation health of personnel as well as users.

In response to the concern above, this work then measured the basic ionisation levels in four main beaches in Delta State and hence determined the ensuing radiation dose equivalent levels. The purpose is to ascertain whether or not the radiation levels in the centres conform to international stipulations and as such determine whether members of the public/respective customers are unduly exposed to radiation.

\section{MATERIALS AND METHODS}

In-situ indoor and outdoor radiation level measurements were carried out in four main beaches in Delta State (Figure 1) using a Raderlert 100 radiation survey meter. These beaches are Abraka River Resort, Ethiope East Local Government, Umuaja (River Ethiope Source), Ukwuani Local Government, Otu Ogwu (Asaba), Oshimili South Local Government and Top Desk, OzoroIsoko South 
Local Government. The precise locations of each of these beaches were determined using a geographical positioning system (GPS). All measurements were made one meter above the ground in accordance with conventional practice. This height which is usually about the waste axis, is also the region of the highly radiosensitive gonads in humans (Ebong and Alagoa, 1992). Maximum response of the meter used for the measurements was ensured by taking the readings between the hours of 1300 and 1600 as recommended by the National Council on Radiation Protection NCRP (NCRP, 1987).

Two measurements were made in each location. At least eight locations were identified in each of the beaches. The mean dose equivalent level for each beach was then calculated from the measured BIR values using the conversion expression (NCRP, 1993):

$1 m R h^{-1}=\frac{(0.96 \times 24 \times 365)}{100} \mathrm{mSvy}^{-1}$

0.96 is the conversion factor, 24 is the number of hours in a day, and 365 is the number of days in a year. The dose equivalent values so obtained were used to calculate certain radiation health parameters applying their appropriate equations. The values of the parameters obtained were then compared with their internationally recommended values with the view of assessing the radiological health status of each of the studied beach environments.

\section{RESULTS AND DISCUSSIONS}

In Table 2, the measured exposure rates as well as the calculated dose equivalents are presented. The mean indoor exposure in the Abraka beach environment is $0.015 \mathrm{mRh}^{-1}$ as against $0.014 \mathrm{mRh}^{-1}$ measured in the beach at Asaba. These values are both higher than the $0.013 \mathrm{mRh}^{-1}$ value stipulated by the International Commission on radiological Protection (ICRP, 2003) an indication that the indoor provisions in these beaches may not be radiologically healthy. The data show that the dose equivalent value obtained in the beach at Abraka ranges from $1.037-1.598 \mathrm{mSvy}^{-1}$. The mean value is $1.282 \mathrm{mSvy}^{-1}$. The corresponding values in the beach at Asaba are $1.009-1.458 \mathrm{mSvy}^{-}$ ${ }^{1}$ and $1.174 \mathrm{mSvy}^{-1}$. Thus with mean level ratio of 1.1: 1 in favour of Abraka, it can be argued that the indoor dose equivalent is slightly higher in the beach at Abraka than in the beach at Asaba. This probably could mean that the buildings in the former are not as ventilated as those in the later. It can also be as a result of the nearness of the former to oil exploration and exploitation activities. These calculated mean values are also higher than the recommended $1 \mathrm{mSvy}^{-1}$ by the ICRP for members of the public (ICRP, 2007). This seems to confirm the radiological unhealthiness of these indoor environments. The values are however much lower than the $20 \mathrm{mSvy}^{-1}$ recommended for radiological workers. The outdoor mean dose rates of $0.010 \mathrm{mRh}^{-1}, 0.013 \mathrm{mRh}^{-1}, 0.012$ $\mathrm{mRh}^{-1}$ and $0,013 \mathrm{mRh}^{-1}$ obtained for the environments of the Abraka, Asaba, Ozoro and Umuaja beaches respectively when compared with the $0.013 \mathrm{mRh}^{-}$ ${ }^{1}$ value recommended by the ICRP (ICRP, 2003), suggest that the outdoor exposure in these beaches seem not to pose any radiological health threat.

From Figure 2, it is observed that the distribution of dose equivalent in the environments of the beaches for either indoor or outdoor varied from one measurement position to another showing a peaking and a falling trend pattern. This pattern has earlier been observed in the Okpara coal mine environment (Mokobia and Balogun, 2004). This Figure also reveals that the measured outdoor radiation levels can be ranked as Asaba $>$ Umuaja $>$ Ozoro $>$ Abraka. It is further observed that the indoor levels are higher than the outdoor. This might be attributable to radiation build up indoors consequent upon the materials used in the construction and finishing of the indoor environments.

In Table 3, the inter beach dose equivalent levels are compared. The indoor level as obtained from this work is averagely 1.11 and 1.47 times outdoor in the beaches at Asaba and Abraka respectively. The range of the indoor to outdoor ratio is $1.12-1.89$ in Abraka beach environment and $1.05-1.13$ in Asaba. Thus as is expected indoor dose equivalent values are higher than the outdoor. Both ranges fall within the $0.6-2.3$ range obtained by Rafique et al (2014) for a valley in Turkey. The plots of indoor against outdoor dose equivalents in Figures 3 and 4 for the Abraka and Asaba beaches show that the linear regression equations expressing the relationship between these variables are:

$(\text { Dose })_{\text {Abrakaindoor }}=0.161(\text { Dose })_{\text {outdoor }}+1.140(3)$ and

$(\text { Dose })_{\text {Asaba indoor }}=0.854(\text { Dose })_{\text {outdoor }}+0.278(4)$

The correlation coefficients are 0.41 and 0.05 respectively. These low coefficients confirm as was observed by Rafique et al (2013) that dose equivalent has no correlation with altitude.

Data in Table 4 show that the values of the calculated radiation health parameter AEDE are (0.20 and 0.19) $\mathrm{mSvy}^{-1}$ indoors and $(0.41$ and 0.53$) \mathrm{mSvy}^{-1}$ outdoors in the Abraka and Asaba beaches. In the Ozoro and Umuaja beaches, the corresponding outdoor values are $(0.47$ and 0.50$) \mathrm{mSvy}^{-1}$. These calculated valuesare all higher than the $0.07 \mathrm{mSvy}^{-1}$ world average (UNSCEAR, 1988). Data in this Table also 
show that the calculated values of ELCR are $(0.67$ and 0.64$) \times 10^{-3}$ indoors and (1.38 and 1.74) $\times 10^{-3}$ outdoors in the Abraka and Asaba beaches while the outdoor values in the Ozoro and Umuaja beach environments are (1.55 and 1.65) $\times 10^{-3}$. All these calculated values are higher than the world average value $0.29 \times 10^{-3}$ (Taskin et al, 2009). The fact that the values of the calculated radiation health parameters in these environments are all higher than their respective world averages again suggests that the environments may not be radiologically safe for workers as well as the users (customers).

Conclusion: From these results, it can be concluded that the radiation levels in the environments of these studied beaches in Delta State are higher than radiation regulatory stipulations. Thus in the present states, these environments are radio logically unhealthy for their respective workers and members of the public.

Recommendation: The result from this work and this consequent conclusion necessitate appropriate actions from such bodies as the Federal Environmental Protection Agency (FEPA), the Nigeria Nuclear Regulatory Agency (NNRA) and the Nigeria Atomic Energy Commission (NAEC) and it is so recommended.

Table 1: Some renowned beaches and their locations

\begin{tabular}{ll}
\hline Name & Location \\
\hline Myrtle (The golf capital of the world) & South Carolina USA \\
Miami & Southern Florida \\
Cancum & Mexico \\
Ka'anapali & Island of Maui \\
Cable & Western Australia \\
Coconut & Nigeria \\
Takwa Bay & Lagos, Nigeria \\
La Campagne Tropicana & Calabar and Port Harcourt, Nigeria \\
Eko Tourist Resort & Lagos \\
\hline
\end{tabular}

Table 2: Measured BIR values $\left(\mathrm{mRh}^{-1}\right)$ and Corresponding Dose Equivalent $\left(\mathrm{mSvy}^{-1}\right)$

\begin{tabular}{|c|c|c|c|c|c|c|c|c|c|c|}
\hline \multirow[b]{2}{*}{ Location } & \multicolumn{5}{|c|}{ Indoor } & \multicolumn{5}{|c|}{ Outdoor } \\
\hline & R1 & $\mathrm{R} 2$ & R3 & Mean I & DEQ & R1 & $\mathrm{R} 2$ & R3 & Mean & DEQ \\
\hline \multicolumn{11}{|c|}{ Abraka River Resort } \\
\hline 1 & 0.015 & 0.011 & 0.012 & 0.0131 & 1.065 & 0.010 & 0.013 & 0.011 & 0.011 & 0.953 \\
\hline 2 & 0.011 & 0.015 & 0.015 & 0.0141 & 1.149 & 0.010 & 0.011 & 0.010 & 0.010 & 0.869 \\
\hline 3 & 0.015 & 0.015 & 0.015 & 0.0151 & 1.261 & 0.010 & 0.013 & 0.011 & 0.011 & 0.953 \\
\hline 4 & 0.021 & 0.015 & 0.021 & 0.0191 & 1.598 & 0.012 & 0.011 & 0.010 & 0.011 & 0.925 \\
\hline 5 & 0.017 & 0.016 & 0.019 & 0.0171 & 1.460 & 0.009 & 0.013 & 0.010 & 0.011 & 0.897 \\
\hline 6 & 0.019 & 0.015 & 0.017 & 0.0171 & 1.430 & 0.008 & 0.009 & 0.010 & 0.009 & 0.757 \\
\hline 7 & 0.013 & 0.011 & 0.013 & 0.0121 & 1.037 & 0.010 & 0.009 & 0.009 & 0.009 & 0.785 \\
\hline 8 & 0.017 & 0.017 & 0.011 & 0.0151 & 1.261 & 0.010 & 0.011 & 0.011 & 0.011 & 0.897 \\
\hline & & & Mean & 0.015 & 51.282 & & & & 0.01 & $10 \quad 0.879$ \\
\hline \multicolumn{11}{|c|}{ Top Desk Global, Ozoro } \\
\hline 1 & - & - & - & - & - & 0.010 & 0.014 & 0.013 & 0.012 & 1.037 \\
\hline 2 & - & - & - & - & - & 0.013 & 0.012 & 0.013 & 0.013 & 1.065 \\
\hline 3 & - & - & - & - & - & 0.013 & 0.011 & 0.009 & 0.012 & 1.009 \\
\hline 4 & - & - & - & - & - & 0.009 & 0.013 & 0.013 & 0.012 & 0.981 \\
\hline 5 & - & - & - & - & - & 0.010 & 0.013 & 0.012 & 0.012 & 0.981 \\
\hline 6 & - & - & - & - & - & 0.013 & 0.010 & 0.013 & 0.012 & 1.009 \\
\hline 7 & - & - & - & - & - & 0.011 & 0.011 & 0.011 & 0.011 & 0.925 \\
\hline 8 & - & - & - & - & - & 0.010 & 0.011 & 0.013 & 0.011 & 0.953 \\
\hline 9 & - & - & - & - & - & 0.012 & 0.011 & 0.010 & 0.011 & 0.925 \\
\hline 10 & - & - & - & - & - & 0.012 & 0.013 & 0.010 & 0.012 & 0.981 \\
\hline & & & & & & & Mean & & 0.012 & 0.987 \\
\hline \multicolumn{11}{|c|}{ River Ethiope Source, Umuaja } \\
\hline 1 & - & & - & - & - & 0.012 & 0.011 & 0.012 & 0.012 & 0.981 \\
\hline 2 & - & - & - & - & - & 0.013 & 0.013 & 0.013 & 0.013 & 1.093 \\
\hline 3 & - & & - & - & - & 0.012 & 0.011 & 0.012 & 0.012 & 0.981 \\
\hline 4 & - & & - & - & - & 0.017 & 0.013 & 0.012 & 0.014 & 1.177 \\
\hline 5 & - & & - & - & - & 0.013 & 0.012 & 0.013 & 0.013 & 1.065 \\
\hline 6 & - & & - & - & - & 0.012 & 0.012 & 0.013 & 0.012 & 1.037 \\
\hline 7 & - & & - & - & - & 0.012 & 0.013 & 0.011 & 0.012 & 1.009 \\
\hline
\end{tabular}

MOKOBIA, CE; ANIKU, T; AVWIRI, G 
$\begin{array}{llllll}8 & - & - & - & - & - \\ 9 & - & - & - & - & - \\ 10 & - & - & - & - & -\end{array}$

Otu Ogwu, Asaba

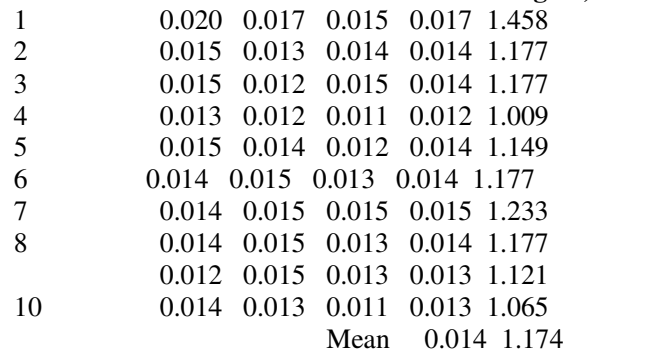

$\begin{array}{lllll}0.013 & 0.012 & 0.013 & 0.013 & 1.069\end{array}$

$\begin{array}{lllll}0.013 & 0.012 & 0.013 & 0.013 & 1.065\end{array}$

$\begin{array}{lllll}0.012 & 0.013 & 0.013 & 0.013 & 1.054\end{array}$

Mean $0.013 \quad 1.054$

Table 3: Comparison of the indoor and outdoor Dose Equivalent $\left(\mathrm{mSvy}^{-1}\right)$

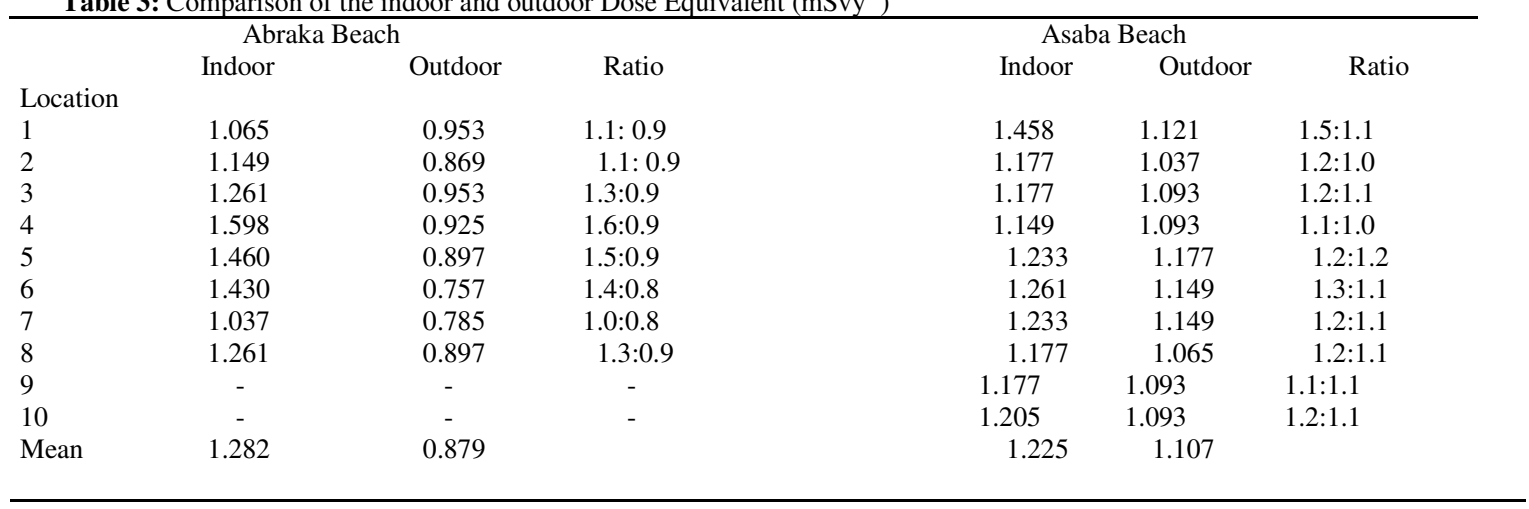

Table 4: Calculated radiological health parameters for the different beach environments

\begin{tabular}{|c|c|c|c|c|c|c|}
\hline \multicolumn{2}{|r|}{ Indoor } & \multicolumn{4}{|c|}{ Outdoor } & \multirow[b]{2}{*}{$\operatorname{ECLR}\left(\mathbf{x 1 0}^{-3}\right)$} \\
\hline & DR $\left(m G y y^{-1}\right)$ & $\operatorname{AEDE}\left(\mathrm{mSvy}^{-1}\right)$ & $\mathbf{E C}$ & $\left.10^{-3}\right)$ DR $\left(\mathrm{mGyy}^{-1}\right)$ & $\operatorname{AEDE}\left(\mathrm{mSvy}^{-1}\right)$ & \\
\hline Abraka & 1.16 & 0.20 & 0.67 & 0.80 & 0.41 & 1.38 \\
\hline Asaba & 1.11 & 0.19 & 0.64 & 1.00 & 0.53 & 1.74 \\
\hline Ozoro & - & - & - & 0.89 & 0.47 & 1.55 \\
\hline Umuaja & - & - & - & 0.95 & 0.50 & 1.65 \\
\hline
\end{tabular}




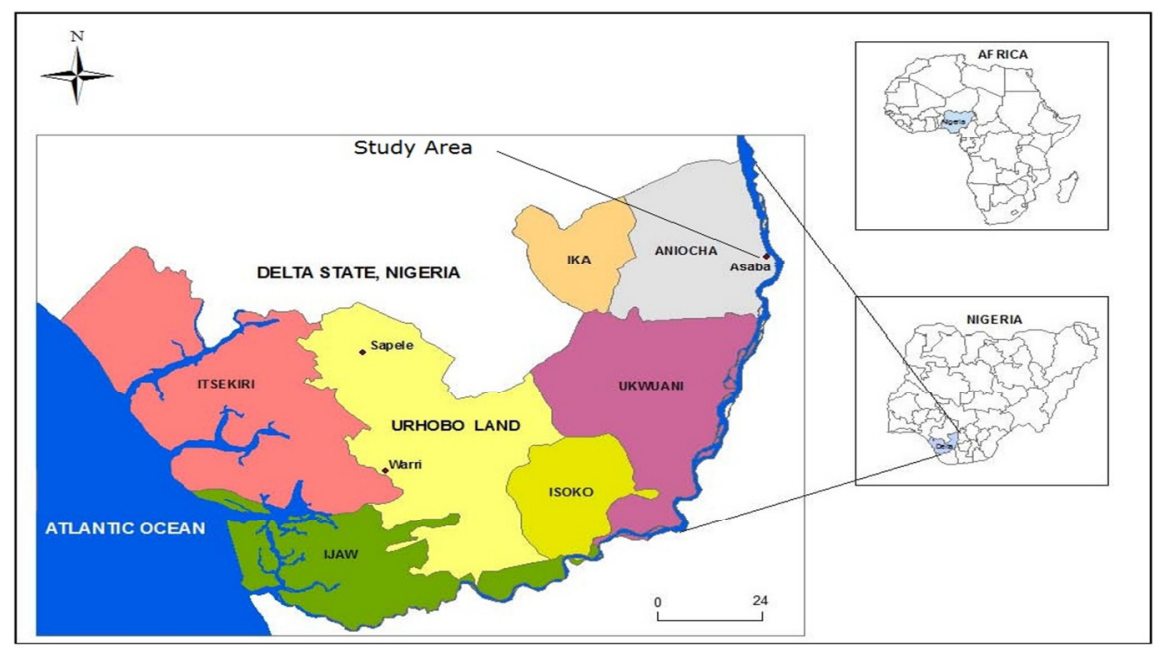

Fig. 1: Map of Delta State showing Ethnic Nationalities (Odemerho, 2008)

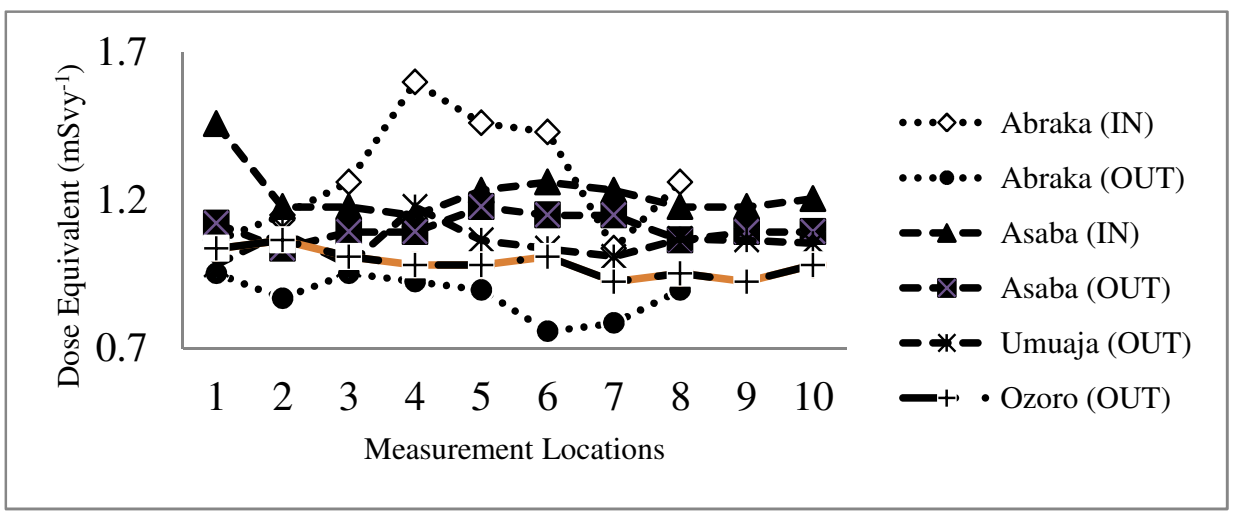

Fig. 2: Dose equivalent levels in different locations at the beaches

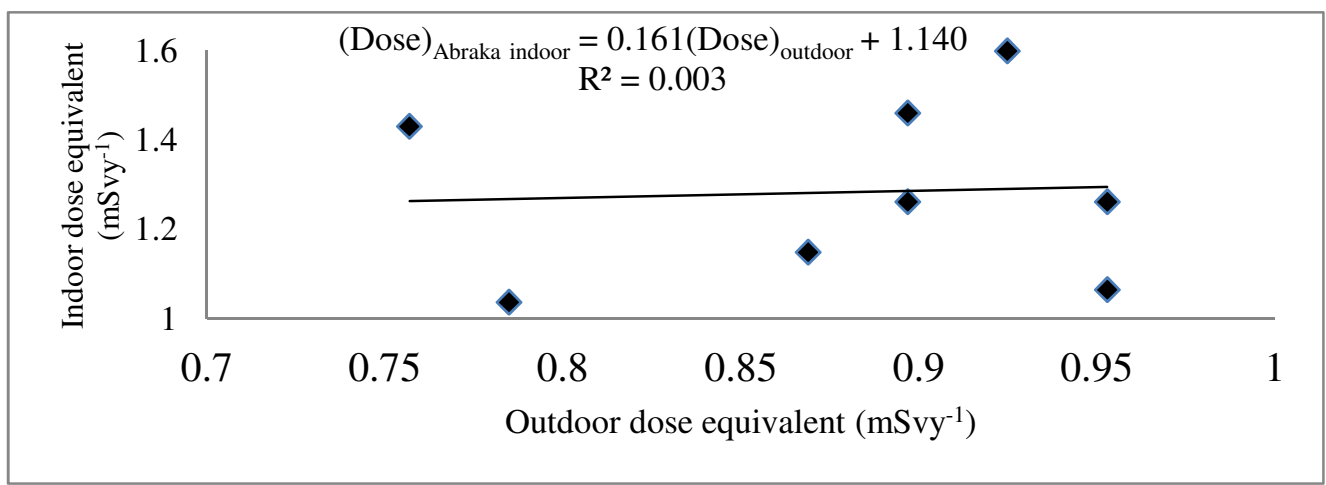

Fig. 3: Graph of indoor against outdoor dose equivalent for Abraka beach 


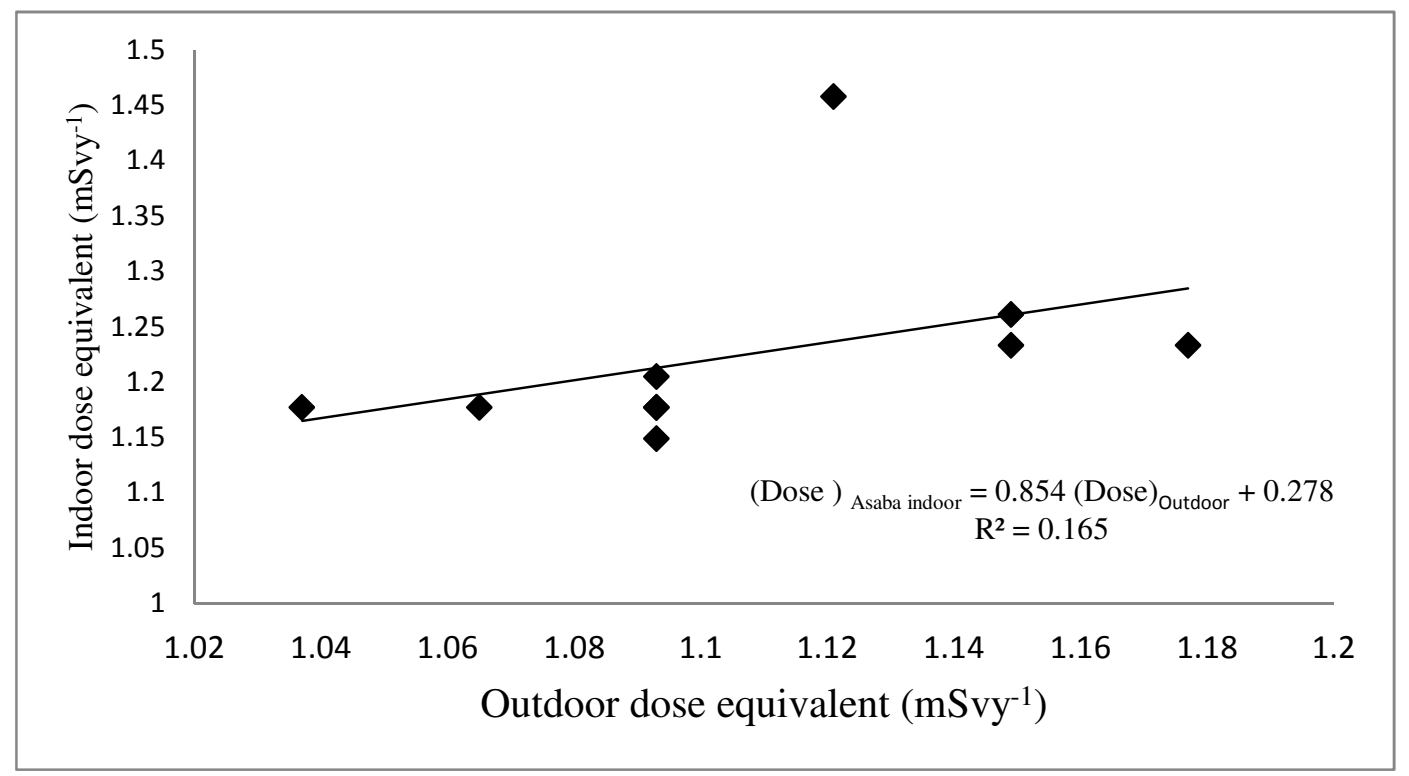

Fig. 4: Graph of indoor against outdoor dose equivalent for Asaba beach

\section{REFERENCES}

Blair and Dawn (2007): Florida's living Beaches, A Guide for the Curious Beach. Pineapple press.

Ebong I.D.U and Alagoa (1992): Fertilizer impact in lonization Radiation Background at a Production Plant.Nig Journal of Physics Vol. 4, 143-149.

ICRP (2007): International Commission on Radiological Protection. The 2007 Recommendation of

the International Commission on Radiological. Protection. ICRP Publication 103

ICRP (2013): International Commission on Radiological Protection. Relative Biological Effectiveness

(RBE), quality factor and radiation weighting factor (WR). A Report of ICRP 33: 1 - 117

Mokobia C.E and Balogun F.A (2004): Background gamma terrestrial dose rate in Nigeriafunctional coal mines. Oxford University Press.

NCRP (1987): National Council on Radiation Protection and Measurements. Ionizing Radiation ExposureOf the population of the United States. NCRP Report 93: Bethesda, Maryland
NCRP (1993): National Council on Radiation Protection and Measurements. Risk Estimates for Radiation Protection. NCRP Report 115, Bethesda, Maryland

Odemerho, F (2008): A map of Delta State showing Urhoboland and other Ethnic nationalities.

Urhobo Historical Society, USA

- $\quad$ www.waado.org/nigeria. Accessed 8/2/16

Rafique, M. Basharat, M. AZharSaeed, R and Rahman, S (2013): Effect of geology and altitudeon ambient outdoor gamma dose rates in district poonch, Azard Kashmir. Carpathian Journal ofEarth and Environmental Sciences, $8.4: 165-173$

Rafique, M. Rahman, S. U. Basharat, M. Aziz, W. Ahmad, I. Lone, K. A. Ahmad, K and

Mattiullah, M (2014): Evaluation of excess life time cancer risk from gamma dose rates in Jhelum valley. Journal of Radiation Research and Applied Sciences, 7.1: 29-35.

Taskin, H. Karavus, M. Ay, P. Topozoglu, A. Hindiroglu, S and Karahan, G. (2009):

Radionuclide concentrations in soil and life time cancer risk due to gamma radioactivity in Kirklareli, Turkey. Journal of Environmental Radioactivity, 100: 49-53 
UNSCEAR (1988): United Nations Scientific Committee on the Effects of Atomic Radiation. Sources,

Effects and Risks of lowering Radiation, Report to the General Assembly with annexes United Nations, New York.

UNSCEAR (2000): United Nations Scientific Committee on the Effects of Atomic Radiation Report vol. 1. Sources, effects and Risks of lowering Radiation- Annex B. Exposures from natural radiation sources. $\quad$ www.unscear.org/unscear.

$\underline{\text { Accessed6/2/16 }}$

UNSCEAR (2013): United Nations Scientific

Committee on the Effects of Atomic Radiation.

Sources and Effects of Ionizing Radiation. Report vol 1. Exposures from natural radiation sources

United Nations New York 